\title{
Egg Production and Egg Quality Characteristics in Direct and Reciprocal Crosses using CARI Nirbheek and CARI Shyama
}

\author{
Jai Prakash ${ }^{1 *}$, Vipin², Kundan Kumar², Yogesh Pandey² and Ravi Kumar Khare² \\ ${ }^{1}$ ICAR-Central Avian Research Institute, Bareilly, Uttar Pradesh, INDIA \\ ${ }^{2} I C A R$ - Indian Veterinary Research Institute, Bareilly, Uttar Pradesh, INDIA \\ *Corresponding author: J Prakash; E-mail:vetjai18@gmail.com
}

Received: 11 April 2020

Revised: 31 May, 2020

Accepted: 05 June, 2020

\begin{abstract}
The present study was carried to study the direct and reciprocal crosses of native breed chickens namely Kadaknath (KN), Aseelpeela (AP), and CARI Red (CR) by comparing the efficiency of egg production, egg weight, and external and internal egg quality traits at $40^{\text {th }}$ week of age. The reciprocal crosses $\mathrm{CR} \times \mathrm{KN}$ and $\mathrm{CR} \times \mathrm{AP}$ showed significantly $(\mathrm{P}<0.01)$ lower egg weights compared to their counterpart cross $\mathrm{KN} \times \mathrm{CR}$ (CARI- Shyama) and $\mathrm{AP} \times \mathrm{CR}$ (CARI- Nirbheek). Egg quality traits such as albumen index, Haugh unit, albumen weight, and yolk index were significantly $(\mathrm{P}<0.01)$ higher in the reciprocal cross at $40^{\text {th }}$ week of age, whereas, others such as shape index, shell thickness, and yolk weight were comparable $(\mathrm{P}>0.05)$ among the crosses. Reciprocal crosses $\mathrm{CR} \times \mathrm{KN}$ and $\mathrm{CR} \times \mathrm{AP}$ had almost similar total egg production to their direct crosses $\mathrm{KN} \times \mathrm{CR}$ and AP $\times$ CR at almost all ages except $36^{\text {th }}$ to $40^{\text {th }}$ week of egg production which was significant $(\mathrm{P}<0.05)$. It was concluded that, reciprocal crosses have similar egg production with almost equal or better egg quality parameters to their direct crosses. The present study aims at the elucidating effect of reciprocal crossbreeding by using CARI Red as the male line in producing elite crosses for improvement in the production capacity of rural poultry in India.
\end{abstract}

\section{HIGHLIGHTS MISSING}

( Comparative evaluation of egg production and egg quality of three poultry breeds.

(0 Egg quality traits were significantly higher in reciprocal crosses.

(0 There was no effect on the egg production between reciprocal and direct crosses.

Keywords: CARI Nirbheek, CARI Shyama, Reciprocal crosses, Egg quality, Egg weight

Rural poultry farming using native breeds has a direct effect on the economy, nutritional status, livelihood security, and critical cultural inputs of the rural population. Native chickens are valuable genetic resources due to their adaptability and disease resistance. The current increase of $46 \%$ (DADF, 2019) from the previous census in a total population of backyard poultry in India, is substantial evidence that regardless of low output from native chickens the desirable characters like small body size, hardiness, consumer preference have made native chickens vital for a balanced farming system in rural households. There is potential for improvement in growth and egg production performance of native chicken by the introduction of high yielding germplasm (Padhi, 2016). Breeding strategy for improvement of native chicken should have the objectives to improve the economic parameters like body weight, egg number, fertility, etc., to get maximum returns by rural farmers while maintaining the characters which are specific to native chicken viz. eggshell colour, long shank length, disease resistance, egg and meat quality to retain its prime status in the market (Das et al., 2017). Among the 19 registered indigenous breeds of chickens in India, the most popular breeds like Aseel and Kadaknath are

How to cite this article: Prakash, J., Vipin, Kumar, K., Pandey, Y. and Khare, R.K. (2020). Egg production and egg quality characteristics in direct and reciprocal crosses using CARI Nirbheek and CARI Shyama. J. Anim. Res., 10(4): 579-683.

Source of Support: None; Conflict of Interest: None 
collected and evaluated at the Central Avian Research Institute, Izatnagar. These two native breeds were crossed with exotic CARI Red as a female line (chosen due to its high egg production potential) for the development of various crosses like CARI-Nirbheek (Aseel Male $\times$ CARI Red female) CARI-Shyama (Kadaknath Male $\times$ CARI Red female) laying 180-190 eggs in period (Kurrey et al., 2019). Some of the stocks developed for the purpose are Chabro (Barred Plymouth Rock $\times$ Red Cornish) Kalinga Brown, Kaveri, Vanaraja, Gramapriya, CARI-Gold, Hitcari, Upcari, Cari-Debendra, Giriraja etc. However, to emphasize both meats as well as egg quality parameters, CARI Red may be utilized as a male line to cross it with native chickens as a female line. The search for a mating system resulting in rapid improvement in economic traits often suffers conflicting reports where some reports suggest positive and significant effect in economic traits of crossbreds in case of direct crosses (exotic cock $\times$ local hen) but not in reciprocal crosses (Native cock $\times$ exotic hen) whereas the reports from other studies point out towards an opposite inference. Nwachukwu et al. (2006) reported higher $(\mathrm{P}<.05)$ egg weights and better egg quality traits in reciprocal crossbreeding between normal local and exotic broiler breeders. Pal et al. (2019) reported better conformation and economic traits in reciprocal crosses Kadaknath (KN), Aseel (AP) and CARI - Red (CR). It was hypothesized that crosses with better meat as well as egg quality parameters can be obtained using a male line of CARI Red with the female line of native chickens. The present study was thus carried out to exploit the males of CARI Red in developing suitable cross for village poultry production for niche markets.

\section{MATERIAL AND METHODS}

The present study was planned for the study of comparative evaluation of crosses reciprocal to CARI Shyama $(\mathrm{KN} \times \mathrm{CR})$ and CARI Nirbheek $(\mathrm{AP} \times \mathrm{CR})$ in the "Desi Fowl Unit" Division of Avian Genetics and Breeding (AG\&B), Central Avian Research Institute (CARI), Izatnagar, Bareilly, U.P., India from December 2017 to May 2018.

\section{Experimental birds}

A breeding plan was followed to get a total of 259 female birds CARI Shyama and CARI Nirbheek along with their reciprocal cross (Table 1). Hens were inseminated by deepintravaginal technique with semen from a selected male (Burrows and Quinn, 1973). The second insemination was done after a day interval and was repeated after every five days to achieve the required number of eggs from each genetic group. Eggs were collected daily after two days of the second stored in an egg holding room $\left(10^{\circ} \mathrm{C}\right)$ for 10 days after marking with genetic group code. Eggs were set, chicks brooded for 6 weeks and then shifted to deep litter system. The study was carried out from the $20^{\text {th }}$ week of age and was continued up to the $52^{\text {nd }}$ week of age for measurement of egg quality and production traits in experimental groups.

Table 1: Grouping of experimental birds

\begin{tabular}{lll}
\hline Group & Description & No. of birds \\
\hline (G1) & $\mathrm{KN} \times \mathrm{CR}($ CARI SHYAMA) & 60 \\
$(\mathrm{G} 2)$ & $\mathrm{CR} \times \mathrm{KN}($ Reciprocal) & 64 \\
(G3) & $\mathrm{AP} \times \mathrm{CR}($ CARI NIRBHEEK) & 62 \\
(G4) & $\mathrm{CR} \times \mathrm{AP}($ Reciprocal) & 73 \\
\hline
\end{tabular}

\section{Management practices}

Standard feeding, as well as other farm management, was followed in all experimental groups of birds and timely recording of required data. A lighting schedule of 16 hours per day was given to laying birds. The birds were allowed ad libitum access to feed and water.

\section{Recording of egg production and quality traits}

For recording data, daily eggs were collected twice a day. Separately group-wise numbering of eggs was done to keep the record every day. The birds with complete recording up to $52^{\text {nd }}$ weeks of age were included for statistical analysis. To determine egg quality traits 30 eggs from each group at the $40^{\text {th }}$ week of age were collected randomly. Thus, a total of 120 eggs taken were analyzed for determining egg quality traits. Soft-shelled, cracked, jumbo, very small-sized, and abnormal eggs were not taken in sampling. The egg weight recorded to the nearest accuracy using an electronic weighing balance. The individual egg was weighed with a $0.01 \mathrm{~g}$ sensitive electronic scale. The shape index was calculated as per Shultz (1953). The average thickness was calculated 
and recorded as the thickness of the shell according to Chowdhary (1987). Albumen weight measured in grams using electronic weighing balance. Albumen index was calculated by using the formula proposed by Heiman and Carver (1936). Individual Haugh unit (Haugh, 1937) score was calculated using the egg weight and albumen height (Doyon et al., 1986). Yolk weight was measured with $0.5 \mathrm{mg}$ accuracy using weighing balance and was expressed in gram $(\mathrm{g})$. Yolk index will be calculated as per the formula of Funk (1948).

\section{STATISTICAL ANALYSIS}

Collected data during the study were analyzed using SPSS (20) with one-way ANOVA (Snedecor and Cochran, 1980). Significant means among groups were compared by Tukey's b test.

\section{RESULTS AND DISCUSSION}

\section{Part period egg production (20-52 week)}

Mean of egg production data measured from $20^{\text {th }}$ to $52^{\text {nd }}$ weeks of age showed no significant changes in reciprocal crosses as compare to their counterpart pure crosses (Table $2)$. Among all crosses, the highest egg production is for $\mathrm{KN} \times \mathrm{CR}(\mathrm{G} 1)$ and the lowest egg production is for $\mathrm{CR} \times \mathrm{AP}$ (G4). The total egg production in reciprocal crosses (G2) $\mathrm{CR} \times \mathrm{KN}(80.75$ eggs) and (G4) $\mathrm{CR} \times \mathrm{AP}$ (72.23 eggs) from $20^{\text {th }}$ to $40^{\text {th }}$ week also did not show significant variation to their respective counterpart pure crosses i.e. (G1) $\mathrm{KN} \times \mathrm{CR}(82.72 \mathrm{eggs})$ and (G3) AP $\times \mathrm{CR}(75.79$ eggs). The maximum egg production from $20^{\text {th }}$ to $52^{\text {nd }}$ week of age for the reciprocal cross was 123.23 eggs for $(\mathrm{G} 2) \mathrm{CR} \times \mathrm{KN}$ and
114.82 eggs for $(\mathrm{G} 4) \mathrm{CR} \times \mathrm{AP}$ and not significant to their respective counterpart crosses, except for egg production from $36^{\text {th }}$ to $40^{\text {th }}$ week were all crosses were significant $(\mathrm{P}<0.01)$. The present study was in close agreement with Ganeshan (2015) who recorded data in different crosses. Singh (2016) also noticed that in similar experiments direct cross $\mathrm{NC} \times \mathrm{CR}(223.9$ eggs) had the highest mean egg production whereas the reciprocal crosses $\mathrm{CR} \times \mathrm{NC}$ (213.3) and $\mathrm{NC} \times \mathrm{AN}$ (173.2) had lowest egg production among all the reciprocal and direct cross. Jai Sunder et al. (2005) on studying progeny of direct and reciprocal crosses of Brown Nicobari with ILI-80 reported little lower annual egg production. Nwachukwu et al. (2006) in their study on main and reciprocal crossbred normal local, (naked-neck $\&$ frizzle chicken $\times$ exotic broiler) reported reciprocal effects in crosses for egg production and egg quality traits. This phenomenon is thought to originate from sex-linked genes or maternal effects, the heavier weight of reciprocal crossbreds inclining towards the weight of exotic dams highlighting the importance of dam line in practical poultry breeding.

\section{Egg weight and egg quality traits}

The mean values in the present study for various egg weight and egg quality traits in different crossing group at $40^{\text {th }}$ and $52^{\text {nd }}$ week of age showed the reciprocal crosses $\mathrm{CR} \times \mathrm{KN}$ and $\mathrm{CR} \times \mathrm{AP}$ have significantly lesser $(\mathrm{P}<0.01)$ egg weight as compared to their counterpart cross $\mathrm{KN} \times \mathrm{CR}$ and $\mathrm{AP} \times \mathrm{CR}$ at both age stages as presented (Table 3 ). Similarly, findings by Jha et al. (2013) and Ganeshan (2015) were near to present investigation and they reported that at $40^{\text {th }}$ week of age, reciprocal crosses $\mathrm{CR} \times \mathrm{AP}$ and $\mathrm{CR} \times \mathrm{KN}$ have $50.39 \mathrm{~g}$ and $51.46 \mathrm{~g}$ egg weight which was lesser than the direct cross in their study.

Table 2: Means $( \pm \mathrm{SE})$ of Egg production in different crosses from $20^{\text {th }}$ to $52^{\text {nd }}$ week of age

\begin{tabular}{lllll}
\hline $\begin{array}{l}\text { Egg productions } \\
(\mathbf{w k s})\end{array}$ & $\begin{array}{l}\text { KN } \times \mathbf{C R} \\
\text { CARI Shyama }\end{array}$ & $\begin{array}{l}\mathbf{C R} \times \mathbf{K N} \\
\text { Reciprocal CS }\end{array}$ & $\begin{array}{l}\text { AP } \times \mathbf{C R} \\
\mathbf{C A R I}\end{array}$ & $\begin{array}{l}\mathbf{C R} \times \mathbf{A P} \\
\text { Reciprocal CN }\end{array}$ \\
\hline $20-28$ & $11.97 \pm 1.29$ & $9.52 \pm 1.14$ & $10.87 \pm 1.42$ & $9.08 \pm 1.11$ \\
$28-32$ & $22.68 \pm 0.93$ & $22.64 \pm 0.82$ & $20.12 \pm 1.23$ & $19.77 \pm 0.93$ \\
$32-36$ & $24.61 \pm 0.52$ & $25.11 \pm 0.38$ & $24.42 \pm 0.77$ & $23.18 \pm 0.48$ \\
$36-40$ & $23.46^{\mathrm{b}} \pm \mathbf{0 . 4 2}$ & $23.48^{\mathrm{b}} \pm \mathbf{0 . 6 0}$ & $20.38^{\mathrm{a}} \pm \mathbf{1 . 0 6}$ & $20.19^{\mathrm{a}} \pm \mathbf{0 . 8 3}$ \\
$40-52$ & $40.83 \pm 1.39$ & $42.53 \pm 1.38$ & $43.33 \pm 1.30$ & $43 \pm 1.52$ \\
$20-52$ & $123.54 \pm 2.92$ & $123.23 \pm 2.51$ & $119.12 \pm 3.39$ & $114.82 \pm 3.00$ \\
\hline
\end{tabular}

${ }^{a b}$ Mean values bearing different superscript in row differ significantly $(\mathrm{P}<0.05)$ 
Table 3: Means $( \pm \mathrm{SE})$ of Egg weight (gram) and Egg quality parameters in different crosses

\begin{tabular}{|c|c|c|c|c|c|c|}
\hline \multicolumn{2}{|l|}{ Egg qualities } & $\begin{array}{l}\mathrm{KN} \times \mathrm{CR} \\
\text { CARI Shyama }\end{array}$ & $\begin{array}{l}\mathrm{CR} \times \mathrm{KN} \\
\text { Reciprocal CS }\end{array}$ & $\begin{array}{l}\text { AP } \times \text { CR } \\
\text { CARI }\end{array}$ & $\begin{array}{l}\mathbf{C R} \times \mathbf{A P} \\
\text { Reciprocal } \mathbf{C N}\end{array}$ & $\mathbf{P}$ \\
\hline \multirow{2}{*}{ Egg weight } & $40^{\text {th }}$ week & $53.18^{\mathrm{b}} \pm 2.92$ & $50.36^{\mathrm{a}} \pm 2.51$ & $55.39^{c} \pm 3.39$ & $52.11^{\mathrm{ab}} \pm 3.00$ & $<0.01$ \\
\hline & $52^{\text {nd }}$ week & $54.75^{\mathrm{b}} \pm 0.50$ & $51.68^{\mathrm{a}} \pm 0.49$ & $57.84^{\mathrm{c}} \pm 0.48$ & $55.36^{\mathrm{b}} \pm 0.52$ & $<0.01$ \\
\hline \multicolumn{2}{|l|}{ Shape Index } & $77.165 \pm 0.31$ & $76.755 \pm 0.57$ & $76.122 \pm 0.57$ & $75.850 \pm 0.64$ & \\
\hline \multicolumn{2}{|c|}{ Albumen Index } & $0.093^{\mathrm{a}} \pm 0.003$ & $0.116^{\mathrm{b}} \pm 0.003$ & $0.117^{\mathrm{b}} \pm 0.004$ & $0.100^{\mathrm{b}} \pm 0.002$ & $<0.01$ \\
\hline \multicolumn{2}{|l|}{ Haugh Unit } & $83.658^{\mathrm{a}} \pm 1.24$ & $88.007^{\mathrm{b}} \pm 1.23$ & $88.606^{\mathrm{b}} \pm 1.51$ & $81.747^{\mathrm{a}} \pm 1.25$ & $<0.01$ \\
\hline \multicolumn{2}{|l|}{ Yolk Index } & $0.386^{\mathrm{a}} \pm 0.004$ & $0.397^{\mathrm{a}} \pm 0.004$ & $0.397^{\mathrm{a}} \pm 0.004$ & $0.422^{b} \pm 0.007$ & $<0.01$ \\
\hline \multicolumn{2}{|c|}{ Albumen Weight } & $30.406^{\mathrm{b}} \pm 0.472$ & $31.731^{\mathrm{b}} \pm 0.584$ & $31.731^{\mathrm{b}} \pm 0.584$ & $27.248^{\mathrm{a}} \pm 0.879$ & $<0.01$ \\
\hline \multicolumn{2}{|l|}{ Yolk Weight } & $15.685 \pm 0.36$ & $16.537 \pm 0.23$ & $16.537 \pm 0.23$ & $15.988 \pm 0.20$ & \\
\hline \multicolumn{2}{|c|}{ Shell Thickness (mm) } & $0.316 \pm 0.004$ & $0.322 \pm 0.004$ & $0.320 \pm 0.004$ & $0.325 \pm 0.006$ & \\
\hline
\end{tabular}

${ }^{a b}$ Mean values bearing different superscript in row differ significantly $(\mathrm{P}<0.05)$.

Among the egg quality traits, only albumen index, Haugh unit, albumen weight, yolk index are showing significant $(\mathrm{P}<0.01)$ difference while other egg quality indices like shape index, shell thickness, yolk weight were nonsignificant. Albumen index of reciprocal crosses, $(\mathrm{CR} \times \mathrm{KN}$ and $\mathrm{CR} \times \mathrm{AP})$ was significant $(\mathrm{P}<0.01)$ to their respective direct crosses $(\mathrm{KN} \times \mathrm{CR}$ and $\mathrm{AP} \times \mathrm{CR})$. Haugh unit of reciprocal crosses $(\mathrm{CR} \times \mathrm{KN}$ and $\mathrm{CR} \times \mathrm{AP})$ was significant $(\mathrm{P}<0.01)$ to their respective direct crosses $(\mathrm{KN} \times \mathrm{CR}$ and $\mathrm{AP} \times \mathrm{CR})$. Similarly, yolk index for reciprocal crosses $(\mathrm{CR} \times \mathrm{KN}$ and $\mathrm{CR} \times \mathrm{AP})$ was significant $(\mathrm{P}<0.01)$ to their respective direct crosses $(\mathrm{KN} \times \mathrm{CR}$ and $\mathrm{AP} \times \mathrm{CR})$. The albumen weights of reciprocal crosses $(\mathrm{CR} \times \mathrm{KN}$ and $\mathrm{CR} \times \mathrm{AP})$ was significant $(\mathrm{P}<0.01)$ to their respective crosses $(\mathrm{KN} \times \mathrm{CR}$ and $\mathrm{AP} \times \mathrm{CR})$. In present finding both reciprocal crosses as compared to their respective direct cross have slightly higher or equal egg quality traits. Nwachukwu et al. (2006) in their study on main and reciprocal crossbred normal local, Nakedneck, and frizzle chicken $\times$ exotic broiler breeder similarly reported reciprocal crossbreds to have significantly $(\mathrm{P}<0.05)$ higher values for egg quality traits except shell thickness and yolk weight. Chatterjee et al. (2007) studied the direct and reciprocal crosses of Brown Nicobari and ILI-80 under the intensive management and backyard system of management and found significant $(\mathrm{P}<0.05)$ difference of shape index, albumen weight, yolk weight, yolk height, shell weight between the progeny of direct and reciprocal crosses corroborating with the present experiment. The present result is in agreement to the finding of (Verma et al., 1983; Kumararaj et al., 1990) and Ganeshan (2015) who found that egg quality traits like shape index, shell thickness, yolk weight did not differ significantly in the reciprocal cross concerning their counterpart crosses in their studies.

\section{CONCLUSION}

Up-gradation of the native breeds of chickens through different breeding techniques helps to increase the productivity and conservation of the germplasm in their natural habitat. It can be concluded that reciprocal crossbreeding positively influences egg-laying and egg quality characters with reciprocal crossbred performing better for many economic traits under study and the use of CARI Red as the male line can help in the production of elite crosses among the presently studied crossbreds.

\section{ACKNOWLEDGEMENTS}

The financial assistance provided to the author in the form of Institutional Fellowship and research grant provided by ICAR is gratefully acknowledged.

\section{REFERENCES}

Burrows, W.J., Quinn, J.P.1973. Collection of spermatozoa from fowl and turkey. Poult. Sci., 16: 19-24.

Chatterjee, R.N., Sharma, R.P., Reddy, M.R., Niranjan, M. and Reddy, B.L.N. 2007. Growth, body conformation and immune responsiveness in two Indian native chicken breeds. Lives. Res. Rur. Develop., 19: 12-14. 
Chowdhary, S.D.1987. Effect of feeding Steolathyrogens to laying fowl (Gallus domesticus) with particular reference to eggshell and membrane quality. Ph. D. Thesis, University of London. U.K.

DAHD. Annual report 2019-20. Department of Animal Husbandry, Dairying and Fisheries, Ministry of Agriculture and Farmers Welfare, Government of India.

Das, A.K., Mishra, A.K., Kumar, S., Rahim, A. and Kokate, L.S. 2017. Characterizing grower performance, body conformation and morphology in crosses of RIR and Indian native chicken genotypes. Indian J. Anim. Sci., 87(6): 118121.

Doyon, G., Bernier-Cardou, M., Hamilton, R.M.G., Castaigne, F. and Randall, C.J. 1986. Albumen quality of egg from five commercial strains of White Leghorn hens during one year of lay. Poult. Sci., 65: 63-66.

Funk, E.M. 1948. The relation of the yolk index determined in natural position to the yolk index as determined after separating the yolk from albumen. Poult. Sci., 27: 376-380.

Ganeshan, S. 2015. Estimation of crossbreeding parameters for production traits under diallel cross of native and exotic breeds of chicken. M.V.Sc. Thesis, Indian Veterinary Research Institute Izatnagar, Bareilly U.P. India.

Haugh, R.R. 1937. The Haugh unit for measuring egg quality. US Egg Poul. magazine., 43: 552-555.

Heiman, V. and Carver, J.S. 1936. Albumen index as a physical measurement of observed egg quality. Poult. Sci., 15: 141148.

Jai, S., ChatterjeeR.N., Rai R.B., Kundu, A., Senani, S., Singh, A. and Jeyakumar, S.2005. Production performances of indigenous and crossbred poultry germplasm of $\mathrm{A}$ and $\mathrm{N}$ Islands.Indian J. Anim. Sci., 75: 1326 - 1328.
Jha, D.K., Prasad, S., Soren, S.K. and Bharti, A. 2013. Production performance of indigenous chicken in intensive farming system. Indian J. Poult. Sci., 48: 105-108.

Kumararaj, R., Kothandaraman, P. and Ulaganathan, V. 1990. Heterosis for growth, reproduction and egg quality in an interstrain cross of White Leghorn. Indian J. Poult. Sci., 25: 13-20.

Kurrey, L., Singh, D.P., Narayan, R. and Vineetha, P.G. 2019. Mortality pattern in a complete diallel cross of AseelPeela, Kadaknath and CARI-Red. Indian J. Vet. Res., 28 (1): 14-17.

Nwachukwu, E.N., Ibe, S.N. and Ejekwu, K. 2006. Short term egg production and egg quality characteristics of main and reciprocal crossbred normal local, naked-neck and frizzle chicken $\mathrm{X}$ exotic broiler breeder stock in a humid tropical environment. J. Anim. Vet. Adv., 5(7): 547-551.

Pal, S., Gupta, T., Wagh, S. and Yadav, D.K. 2019. Comparisons of growth performance of direct and reciprocal crosses of Aseel Peela (AP) and Kadaknath (KN) with Cari-Red. $J$. Entomol. Zool. Stud., 7(2): 1356-1359.

Padhi, M.K. 2016.Importance of indigenous breeds of chicken for rural economy and their improvements for higher production performance. Scientifica.

Singh, V., 2016. Estimation of crossbreeding parameters for production traits incomplete diallel cross involving two native and one exotic chicken breeds Ph.D. Thesis, Indian Veterinary Research Institute Izatnagar, Bareilly, U.P. India.

Snedecor, G.W. and Cochran, W.G. 2004. Statistical Methods. $8^{\text {th }}$ Edn., East West Press Pvt. Ltd., New Delhi.

Verma, S.K., Pani, P.K. and Mohapatra, S.C. 1983. Studies on additive and non-additive genetic effects of yolk Index, albumen quality and shell thickness in White Leghorn birds. Indian J. Poult. Sci., 18: 28-32. 
